Chemistry and Ecology

December 2005, Volume 21, Issue 6, pages 503 - 509

http://dx.doi.org/10.1080/02757540500439217

(c) 2005 Taylor \& Francis group. Informa
Archimer http://www.ifremer.fr/docelec/ Archive Institutionnelle de l'Ifremer

The original publication is available at http://www.tandf.co.uk/journals/

\title{
Grazing affects carbon fixation pathways by phytoplankton in coastal marine ecosystems
}

\author{
Y. Collos ${ }^{a,}{ }^{*}$, C. Descolas-Gros ${ }^{b}$, F. Mornet $^{c}$ \\ a Laboratoire Ecosystèmes Lagunaires (UMR CNRS 5119), Université Montpellier II, CC093, Montpellier Cedex 5 , \\ France \\ ${ }^{\mathrm{b}}$ Institut des Sciences de l'Evolution (UMR CNRS 5554), Université Montpellier II, CC065, Montpellier Cedex 5 , \\ France \\ ${ }^{c}$ Centre de Recherche en Ecologie Marine et Aquaculture (UMR 10 CNRS-IFREMER), BP 5, L'Houmeau, France \\ *: Corresponding author : Collos Y., email address : $\underline{\text { Yves.Collos@univ-montp2.fr }}$
}

\begin{abstract}
:
During parallel sampling of seawater samples in bottles and in free water (1000-2000 $\mathrm{m}^{3}$ clay ponds), we have measured phytoplankton biomass, Ribulose biphosphate carboxylase (Rubisco), phosphoenol pyruvate carboxylase, and phosphoenol pyruvate carboxykinase activities and major nutrients (ammonium, nitrate, phosphate, silicate). This was done in two ecosystems: one with high grazing pressure due to the presence of oysters and another with low grazing pressure (no oysters). In the ecosystem subjected to high grazing pressure, anaplerotic carbon fixation by phytoplankton in free water was higher in the light period and could represent $25 \%$ of total carbon fixation. Incubating samples in bottles led to a major increase in Rubisco activity ( $80 \%$ in $3 \mathrm{~h}$ ) relative to values measured in free water, a decrease in $\beta$-carboxylases activity $(70 \%$ in $24 \mathrm{~h})$ due to ammonium exhaustion, as well as disappearance of its diel periodicity. This indicates a contrario that grazers, which are excluded from incubation bottles, drive ecosystems toward heterotrophy in situ by favoring the $\beta$-carboxylation pathway through excretion products such as ammonium. Therefore, incubations in high grazing environments (characterized by a grazing rate near 2 day $^{-1}$ ) change the way carbon is fixed by unicellular algae within $3 \mathrm{~h}$ through a change in the form of nitrogen taken up.
\end{abstract}

Keywords: Ammonium; Anaplerotic; Carbon assimilation; Carboxylases; Grazing 
Two major pathways of carbon assimilation are responsible for phytoplankton growth in aquatic systems. One is the ribulose biphosphate carboxylase (Rubisco) pathway (Calvin-Benson cycle), and the other one is the ßcarboxylase (anaplerotic) pathway. The latter one is generally considered to be quantitatively of minor importance [1], excepted in transient situations of nitrogen supply [2] which are often considered to dominate in aquatic ecosystems $[3,4,5]$ and in heterotrophic nutrition $[6$, 7, 8]. Rubisco uses light as an energy source, while the ßcarboxylases use internal or external metabolites [8]. Bcarboxylases activities are also known to depend on ammonium in the medium of cultures of unicellular algae $[9,10]$. This anaplerotic carbon fixation allows the synthesis of molecules that are essential for growth and cannot be provided by the Calvin-Benson cycle [11]. Here we examine the possibility that enclosing water samples has an effect on the activities of those enzymes and the rerouting of carbon relative to the situation in situ, where macrograzers are present [12, 13]. Traditional measurements of primary production in aquatic ecosystems are generally carried out by adding isotopic carbon tracers to water samples and incubating those in containers of various sizes and materials $[14,15]$. While this approach has been criticized in many respects, it still remains the main way by which global fluxes of carbon are estimated in the oceans $[16,17]$. One difficulty of validating the widely used incubation method comes from the movement of water masses in situ which makes comparisons between free water and incubated water impossible to carry out. Here we report such comparisons by using enzymatic measurements which do not require incubations and mesocosms which are large enough to support several trophic levels [18] but are still manageable in terms of homogeneity and size to allow large scale extrapolations from point sampling. 
Materials and methods

To test the effect of incubation on carboxylating enzymes, we compared changes in bulk nutrients, phytoplankton biomass and carboxylase activities with changes in the same variables measured on samples enclosed in bottles and incubated in the same water body. Sampling took place from two mesocosms which had been filled with fresh seawater during the previous high tide [19]. These were $1000-2000 \mathrm{~m}^{3}$ clay ponds on the Atlantic coast of France (CREMA experimental site). The main difference between the two mesocosms was the presence of oysters and sediment filter feeders in one (high grazing system), which made it similar to a continous culture, with relatively low steady-state chlorophyll a levels (4-10 $\mu \mathrm{g}$ chl a/l) but nevertheless high phytoplankton growth rates [20]. The other one (low grazing system) acted more like a batch culture, with high phytoplankton biomass levels (20-150 $\mu \mathrm{g}$ chl a/l) reached within a few days after filling and isolation from the feed channel. Preliminary tests showed the water column of the mesocosms to be homogenous in chemical and biological properties [19]. Measurements took place in the summer (July) and lasted about $40 \mathrm{~h}$, with a sampling interval ranging from 2 to $12 \mathrm{~h}$.

Samples were taken directly from the mesocosms (referred to as "in situ" in the text) and from mesocosm water enclosed in bottles. Large volume (4 to 8 liter) transparent polycarbonate bottles were filled at time zero with surface seawater, sealed and incubated at the surface of the mesocosms. Aliquots were taken for nutrients (ammonium, nitrate, soluble reactive phosphorus, silicate), particulate matter and enzymatic analysis. Chlorophyll a (collected on Whatman GF/F filters) was extracted in 90\% acetone [21] within 30 min of collection. Bacteria were estimated by epifluorescence direct counting [22]. Nutrients (ammonium, nitrate, phosphate, silicate) 
were measured on a continuous flow analyzer [23].

For carboxylating enzyme assays, samples were collected by filtering 250 to 750 $\mathrm{ml}$ of sea water through GF/F filters which were placed immediately in cryotubes and stored in liquid nitrogen. This storage did not affect the enzyme activities [24].

Activities were determined by measuring the incorporation of radioactive bicarbonate at $25^{\circ} \mathrm{C}$ into stable products. Ribulose biphosphate carboxylase (Rubisco), phosphoenol pyruvate carboxylase (PEPC), and phosphoenol pyruvate carboxykinase (PEPCK) activities were measured in the same extract $[8,24]$.

We did not have replicate bottles, but we used several bottles in series because of the large volumes required for all analyses. Those bottles were all monitored by in vivo fluorescence in order to have an idea of the reproducibility, at least at the level of chlorophyll a fluorescence. From this variability, we could compute a coefficient of variation of about $8 \%$ at the beginning of incubation to about $3 \%$ at the highest values observed.

Results

Table 1 shows the range of variables during the experiment. In the low grazing system, the large phytoplankton was dominated by Prorocentrum minimum, Scrippsiella trochoidea and Gymnodinium spp. In the high grazing system, the diatom Surirella et Diploneis genera dominated. Water temperature ranged between 21.8 and $24.5^{\circ}$ C. Soluble reactive phosphorus (SRP) and silicate concentrations remained high and were not limiting phytoplankton growth.

In the low grazing mesocosm, the incubation did not change the phytoplankton biomass or the activities of either Rubisco or ßcarboxylases relative to the free water 
situation, at least on time scales of 1-2 days used here (Fig. 1). In contrast, in the mesocosm under high grazing pressure, the first obvious effect of incubation was a large (five fold) increase in phytoplankton biomass (Fig. 1) which was due to release of macrograzing pressure. In the free water, the biomass remained low (4-8 $\mu \mathrm{g} / \mathrm{l})$ and exhibited a diel periodicity with lower values at night than during the day.

At the level of carbon fixation enzymes, Rubisco/chla activity in the bottles increased by about $80 \%$ relative to free water activity within 3 h (Fig. 2), overriding the strong diel periodicity observed in the free water and related to the day-night cycle. Over the longer term (days), this activity decreased because of nutrient depletion (dissolved inorganic nitrogen decreased from about 8 to $1 \mu$ molN..$^{-1}$ ). In parallel, Bcarboxylase activities decreased by about $70 \%$ in incubation bottles relative to their activities in the free water on the second day (Fig. 3). We have expressed Bcarboxylase activity on the basis of chl a because bacterial biomass decreased over the experiment [25], so that the trends shown are mostly due to phytoplankton. The higher ßcarboxylase activity during the day also confirms that anaplerotic carbon fixation is higher in the light than in the dark [26]. In the low grazing system, Bcarboxylase activity remained low and similar in bottles and in free water over the duration of the experiment (Fig. 3).

The activity of ßcarboxylases was closely related to ammonium concentrations in the high grazing system $(\mathrm{r}=0.887, \mathrm{p}=0.0001)$ while much more loosely in the low grazing system $(r=0.617, p=0.0326)$. As ammonium decreased with time both in incubation bottles and in free water, ßcarboxylase activity also decreased with time, but in a faster way in the incubation bottles because the ammonium supply from macrograzers was missing and ammonium concentration decreased in a faster way than in free water. 
In fact, the relationship between ammonium in free water and in bottles was much more variable in the high grazing system $(r=0.704, p=0.0131)$ than in the low grazing system $(\mathrm{r}=0.975, \mathrm{p}=0.0001)$, which is expected because the ammonium excreted by the grazers in free water is not present in incubation bottles where the major grazers (oysters and sediment filter feeders) are excluded with $100 \%$ efficiency. In addition, the slope of the relationship was not different from unity in the low grazing system, while ammonium decreased more rapidly (by about 30\%) in bottles than in free water in the high grazing system.

Discussion

The high phytoplankton growth rate $\left(2.6\right.$ divisions.day ${ }^{-1}$, or 1.8 day $\left.^{-1}\right)$ estimated for the high grazing environment was obtained from net increases in chl a concentrations in bottles. The lack of a similar increase in phytoplankton biomass in situ (Fig. 1) implies that grazing is in equilibrium with growth and is also equal to 1.8 day $^{-1}$. This value is in the high range of grazing rates recorded in aquatic environments [27] and is close to the value of 2.1 day $^{-1}$ observed by others at an oyster farming site [28]. The discrepancy in phytoplankton growth estimates between incubation and in free water methods is likely to be a function of the grazing intensity of grazers that are excluded from bottles. Our high grazing mesocosm is therefore probably a worst case scenario exemplified by the wide divergence between the evolutions of biomass (Fig. 1) Rubisco (Fig. 2) and Bcarboxylases (Fig. 3). Concerning rates of carbon fixation, Fig. 2 and 3 show that such rates begin to diverge widely beyond 3 hours of incubation. This duration would then be the upper limit for obtaining representative estimates of rates when using incubation bottles in such environments. The effect of grazing of 
microzooplankton in incubation bottles can be accounted for by using the so called dilution method [29]. However, this does not account for grazers outside incubation bottles. In a recent review of zooplankton grazing [30], it was estimated that the latter consumed about $40 \%$ of phytoplankton daily growth in coastal environments.

Concerning the ecological implications of the use of bottle incubations in relation with the ammonium/heterotrophy link, the diverging trends in Rubisco activity between incubated and free water in the high grazing system (Fig. 2) indicate that the enclosed phytoplankton is less dependent on ammonium or dissolved organic matter excreted by the excluded grazers (less heterotrophy) due to the confinement in bottles and relies more on inorganic carbon (and nitrate) for its nutrition. In addition, the rapid decrease in ammonium concentrations in bottles in the high grazing system leads to a decrease in ßcarboxylase activity. This results in a greater reliance on other nitrogen forms such as nitrate and a switch from regenerated production (on ammonium) to new production (on nitrate). Therefore, incubations in high grazing environments change the way carbon is fixed by unicellular algae through a change in the form of nitrogen taken up.

A strong feedback thus exists between macrograzers and carbon assimilation pathways in phytoplankton, through excreted nitrogenous nutrients, here represented by ammonium. As ßcarboxylase activity is generally associated with heterotrophy $[6,7,8]$, the above relationship can also be considered as representing heterotrophy on the nitrogen level. The traditional "incubation cum tracer" method thus severs the regeneration link and the ammonium supply from macrograzers. This further leads to underestimate heterotrophy whose importance has been shown by other approaches in both marine [31] and freshwater [32] ecosystems. 
References

[1] P. G. Falkowski, J. A. Raven. Aquatic photosynthesis, p. 375, Blackwell Science, Malden (1997).

[2] R. D. Guy, G. C. Vanlerberghe, D. H. Turpin, D.H. Significance of phosphoenolpyruvate carboxylase during ammonium assimilation. Plant Physiol 89, 1150 (1989).

[3] R.C. Dugdale. Modeling. In The Sea, E. D. Goldberg, I. N. McCave, J. J.

O’Brien, J.H. Steele (Eds.), pp. 789-806, Wiley-Interscience, New York (1977).

[4] J.J. McCarthy. The kinetics of nutrient utilization. In Physiological bases of phytoplankton ecology, T. Platt (Ed.), pp. 211-233, Can. Bull. Fish. Aquat. Sci. (1981). [5] J.C. Goldman. Oceanic nutrient cycles. In Flows of energy and materials in marine ecosystems. Theory and practice, M. J. R. Fasham (Ed.), pp. 137-170, Plenum Press, New York (1984).

[6] J.G. Peak, M.J. Peak. Heterotrophic carbon-dioxide fixation by Euglena function of phosphoenolpyruvate carboxylase. Biochem. Biophys. Acta 677, 390 (1981). [7] E. Pönsgen-Schmidt, T. Schneider, U. Hammer, A. Betz. Comparison of phosphoenolpyruvate carboxykinase from autotrophically and heterotrophically grown Euglena and its role during dark anaerobiosis. Plant Physiol. 86, 457 (1988).

[8] C. Descolas-Gros, L. Oriol. Variations in carboxylase activity in marine phytoplankton cultures. ß-carboxylation in carbon flux studies. Mar. Ecol. Prog. Ser., 85, 163 (1992).

[9] H.J. Rosslenbroich, G. Döhler. Einfluß von Ammonium und Nitrat auf die photosynthetische CO2-Fixierung von Bellerochea yucatanensis v. Stosch. Biochem. Physiol. Pfl., 177, 363 (1982). 
[10] G.C. Vanlerberghe, K.A. Schuller, R.G. Smith, R. Feil, W.C. Plaxton, D.H.

Turpin. Relationship between $\mathrm{NH}_{4}$ assimilation rate and in vivo phosphoenolpyruvate carboxylase activity: regulation of anaplerotic carbon flow in the green alga

Selenastrum minutum. Plant Physiol. 94, 284 (1990).

[11] D.T. Dennis, D.H. Turpin. Plant physiology, biochemistry and molecular biology, p. 529, Longman Scientific \& Technical, Essex (1990).

[12] K. Banse, K. Zooplankton : Pivotal role in the control of ocean production. ICES J. Mar. Sci. 52, 265 (1995).

[13] B.W. Frost. A modeling study of processes regulating plankton standing stock and production in the open subarctic Pacific Ocean. Prog. Oceanogr. 32, 17 (1993).

[14] E. Steemann Nielsen. The use of radioactive carbon (14C) for measuring organic production in the sea. J. Cons. Perm. Int. Explor. Mer, 18, 117 (1952).

[15] G. Slawyk, Y. Collos, J. C. Auclair. 1977. The use of the ${ }^{13} \mathrm{C}$ and ${ }^{15} \mathrm{~N}$ isotopes for the simultaneous measurement of carbon and nitrogen turnover rates in marine phytoplankton. Limnol. Oceanogr. 22, 925 (1977).

[16] W.H. Berger, V. S. Smetacek, G. Wefer. Ocean Productivity and Paleoproductivity-An Overview. In Productivity of the Ocean: Present and Past, W.H. Berger, V. S. Smetacek, G. Wefer (Eds.), pp. 1-34, John Wiley \& Sons Limited, (1989). [17] A. Longhurst, S. Sathyendranath, T. Platt, C. Caverhill. An estimate of global primary production in the ocean from satellite radiometer data. J Plankton Res. 17, $1245(1995)$.

[18] T.R. Parsons. The future of controlled ecosystem enclosure experiments. In Marine mesocosms, G. D. Grice, M. R. Reeve (Eds.), pp. 411-418, Springer-Verlag, New York (1982).

[19] Y. Collos, F. Manaud, B. Ravail, A. Cronin, S. Chaigneau. Phytoplankton growth 
dynamics in temperate coastal marine ponds subjected to natural perturbations. In Algal Biotechnology, T. Stadler, J. Mollion, M. C. Verdus, Y. Karamanos, H. Morvan, D. Christiaen (Eds.), pp. 345-353, Elsevier Applied Science Publications, London (1988). [20] J. M. Sornin, Y. Collos, D. Delmas, M. Feuillet-Girard, D. Gouleau. Nitrogenous nutrient transfers in oyster ponds: role of sediment in deferred primary production. Mar. Ecol. Prog. Ser. 68, 15-22 (1990).

[21] O. Holm-Hansen, C. J. Lorenzen, R. W. Holmes, J. D. H. Strickland. Fluorometric determination of chlorophyll. J. Cons. Perm. Int. Explor. Mer 30, 3-15 (1965).

[22] J.E. Hobbie, R.J. Daley, S. Jasper. Use of Nuclepore filters for counting bacteria by fluorescence microscopy. Appl. Environ. Microbiol. 33, 1225-1228 (1977).

[23] K. Grasshoff, Ehrhardt, M., Kremling, K.. Methods of seawater analysis, p. , Verlag Chemie, Weinheim (1983).

[24] C. Descolas-Gros, M.R. Fontugne. Carbon fixation in marine phytoplankton: carboxylase activities and stable carbon -isotope ratios; physiological and paleoclimatological aspects. Mar. Biol. 87, 1-6 (1985).

[25] Y. Collos, C. Descolas-Gros, M. Fontugne, A. Mortain-Bertrand, M. J.

Chrétiennot-Dinet, M. G. Frikha. Chemical, isotopic and enzymatic monitoring of free and enclosed seawater: implications for primary production estimates in incubation bottles. Mar. Ecol. Prog. Ser. 93, 49 (1993).

[26] J.A. Raven. In The intact chloroplast, J. Barber (Ed.), pp. 403-443, Elsevier, Amsterdam (1976).

[27] M. C. Murrell, R. S. Stanley, E. M. Lores, G. T. DiDonato, D. A. Flemer. Linkage between microzooplankton grazing and phytoplankton growth in a Gulf of Mexico estuary. Estuaries 25, 19 (2002). 
[28] M. J. Dagg. Ingestion of phytoplankton by the micro- and mesozooplankton communities in a productive estuary. J. Plankton Res. 17, 845 ( 1995).

[29] M. R. Landry, R. P. Hassett. Estimating the grazing impact of marine microzooplankton. Marine Biology 67, 283 (1982).

[30] A. Calbet, M. R. Landry. Phytoplankton growth, microzooplankton grazing, and carbon cycling in marine systems. Limnol. Oceanogr. 49, 51 (2004).

[31] S.V. Smith, F.T. Mackenzie. The ocean as a net heterotrophic system: implications from the carbon biogeochemical cycle. Global Biogeochemical Cycles 1, 187 (1987). [32] J.J. Cole, N.F. Caraco, G.W. Kling, T.K. Kratz. Carbon-dioxide supersaturation in the surface waters of lakes. Science 265, 1568 (1994)

Table 1. Ranges of chemical and biological variables during the experiment SRP: soluble reactive phosphorus; $\mu$ max: maximum net growth rate from increases in chlorophyll a.

$$
\text { Low grazing High grazing }
$$
Ammonium $\left(\mu \mathrm{mol} \mathrm{N} .1^{-1}\right)$
$1.1-7.1$
$0.6-5.7$
Nitrate
$0.1-4.0$
$0.5-2.2$
Phosphate (SRP)
$4.1-9.0$
$1.3-2.6$ 
Silicate

Chl a $\left(\mu \mathrm{g} .1^{-1}\right)$

$\mu \max \left(\right.$ div.day $\left.^{-1}\right)$

Phytoplankton

Large

Small $3-5 \mu \mathrm{m}\left(10^{6}\right.$ cells. $\left.1^{-1}\right)$

Bacteria $\left(10^{7}\right.$ cells. $\left.\mathrm{ml}^{-1}\right)$
$14.9-36.0$

$13-25.4$

$16-27$

$4-22$

3.8

2.6

dinoflagellates

diatoms

150

1.5

$2.5-3.3$

$8.3-9.7$

Figure legends

Figure 1. Changes in phytoplankton biomass with time in the high grazing mesocosm in situ (squares) and incubated (circles) samples, and in the low grazing mesocosm in situ (diamonds) and incubated (triangles) samples. Dark bars represent night time.

Figure 2. Changes in ribulose biphosphate carboxylase (Rubisco) activity per unit chlorophyll a with time in the high grazing mesocosm in situ (squares) and incubated (circles) samples, and in the low grazing mesocosm in situ (diamonds) and incubated (triangles) samples. Units in $\mathrm{nmol} \mathrm{CO}_{2} \mu \mathrm{g} \mathrm{Chl} \mathrm{a}^{-1} \mathrm{~h}^{-1}$. Dark bars represent night time. 
Figure 3. Changes in Bcarboxylase activity per unit chlorophyll a with time in the high grazing mesocosm in situ (squares) and incubated (circles) samples, and in the low grazing mesocosm in situ (diamonds) and incubated (triangles) samples. Units in nmol $\mathrm{CO}_{2} \mu \mathrm{g} \mathrm{Chl} \mathrm{a}{ }^{-1} \mathrm{~h}^{-1}$. Dark bars represent night time. 


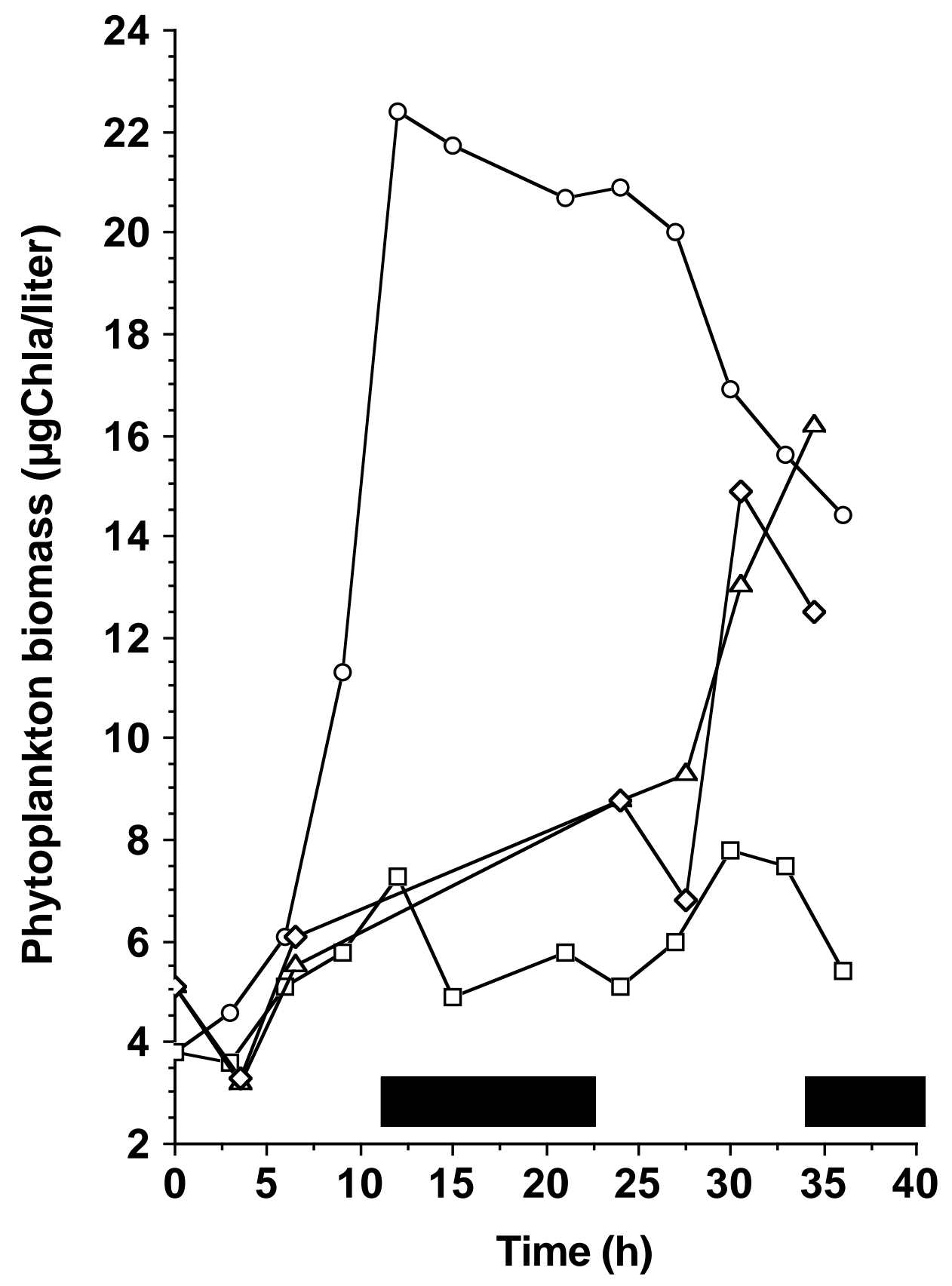

Figure 1 


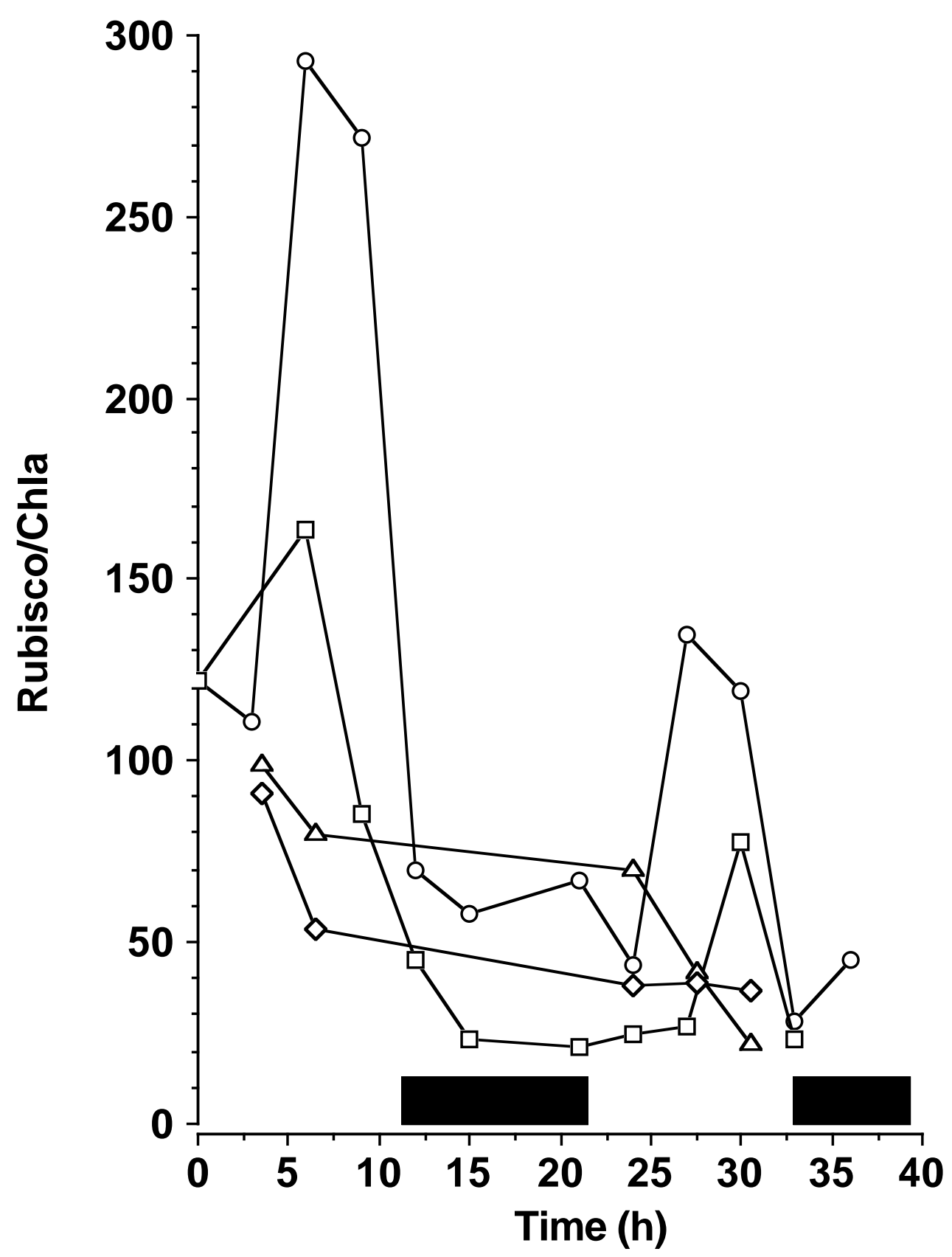

Figure 2 


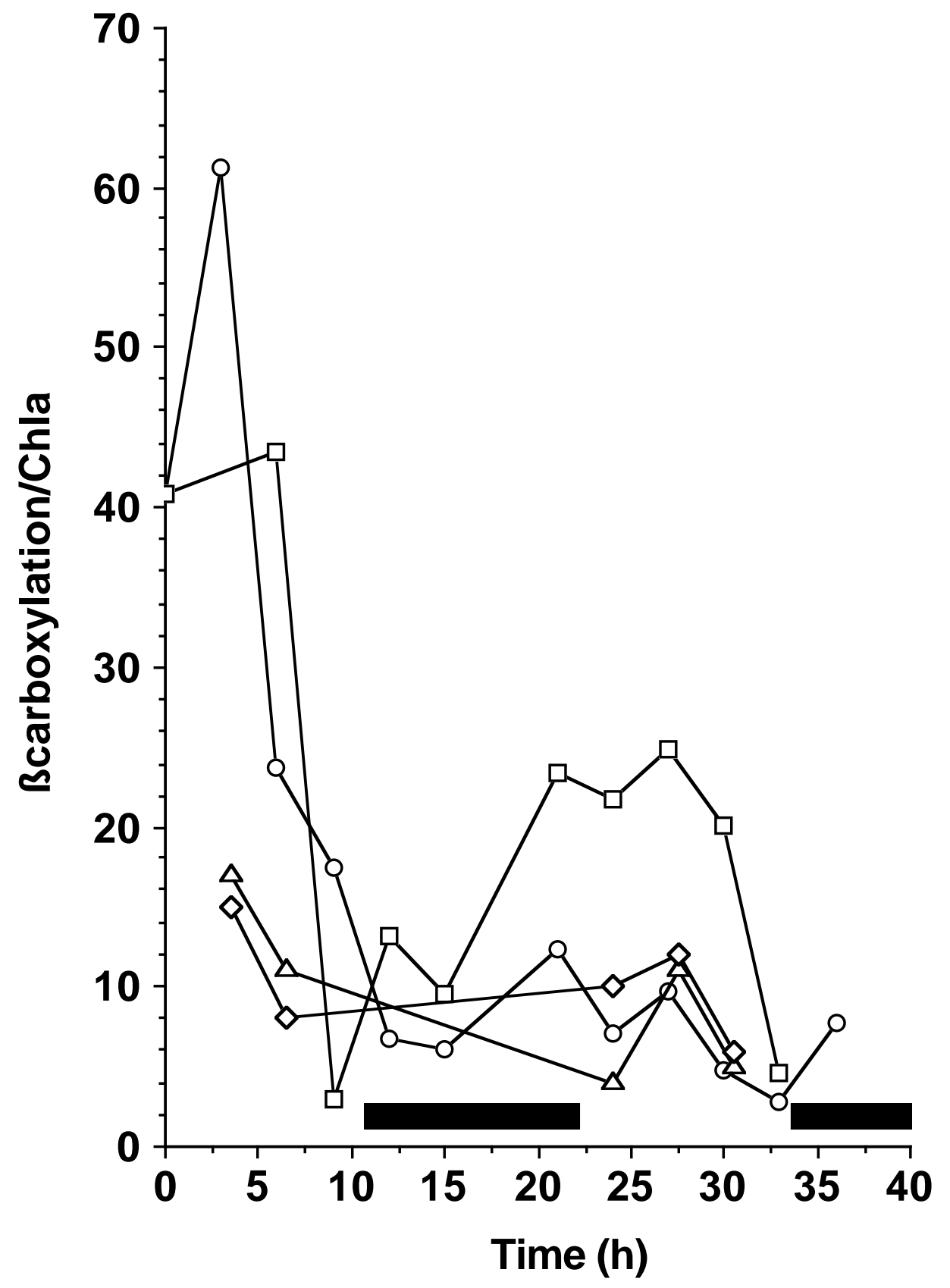

Figure 3 